\title{
SCLERAL LEDGE IN CATARACT INCISION* A CAUSE OF RUPTURE OF THE CAPSULE
}

\author{
BY
}

\author{
G. S. SIHOTA \\ Poona, India
}

BEFORE the introduction of alpha-chymotrypsin (A.C.T.) in cataract surgery by Joaquin Barraquer (1958), the zonule had to be broken manually in all intracapsular extractions, and the two most common methods were:

(1) To hold the anterior capsule of the lens with forceps at the 6 o'clock meridian just in front of the equator and to tumble the lens out;

(2) To hold the anterior capsule at 12 o'clock as near the equator as possible and to lift the lens straight up without tumbling.

Most surgeons seem to favour the former method. Even when the erisophake is used instead of forceps, the technique of zonulolotomy and delivery of the lens remains essentially the same. Since the introduction of A.C.T., however, mechanical zonulolotomy has been replaced by enzymatic zonulolysis and the extraction of the lens by seizing it at the 12 o'clock position is being increasingly practised.

Rupture of the capsule used to be attributed to the toughness of the zonule, but it is now observed that even enzymatic zonulolysis has failed to eliminate this complication, which has been reported by various authors using both forceps and the erisophake.

The obstruction caused by the scleral ledge formed by the posterior lip of the incision to the equator of the lens appears to be responsible for most ruptured capsules after the use of A.C.T., but to the best of my knowledge, neither the scleral ledge nor its role in causing rupture of the capsule has been specifically mentioned in the literature before.

\section{Operative Technique}

This study is based on 48 patients aged 40 to 60 years operated on by the author for senile cataract between April, 1961, and December, 1962. The same technique was used in all cases.

A von Graefe incision was made through the limbus, leaving no conjunctival flap. The incision, which was usually a little less than half the circumference of the cornea, was then enlarged to at least half the circumference with scissors. A complete iridectomy was done in all cases. Three

* Received for publication January 22, 1963. 
post-placed corneo-scleral silk sutures were used in each case at 10.30, 12, and 1.30 o'clock, and $1 \mathrm{ml}$. A.C.T. in a freshly prepared 1:5,000 solution (Quimotrase) was introduced into the posterior chamber by a lacrimal cannula and allowed to act for 3 minutes.

Arruga's forceps were used for the extraction of the lens. During extraction, the cornea was retracted downwards by means of the corneal part of the central corneo-scleral suture, as in Barraquer's so-called "open-sky" technique. The lens was grasped at 12 o'clock and lifted straight out.

Capsule ruptures were frequent in the course of my early attempts to remove the lens by holding it at the top, and this was particularly disappointing as I expected the delivery after zonulolysis to be easy. I soon realized, however, that the chief reason was the obstruction offered to the equator of the lens by the ledge formed by the scleral lip of the corneo-scleral incision (Figure).

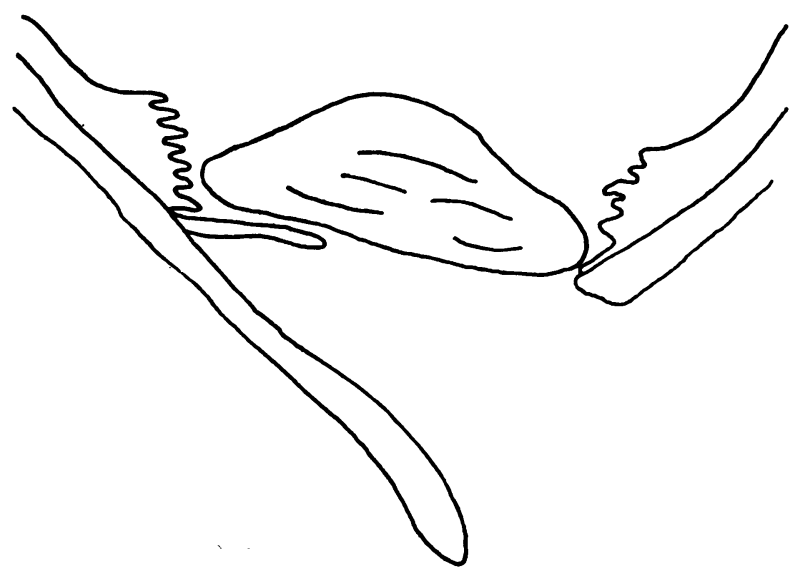

FIGURE.-Complete iridectomy showing scleral ledge.

Because of long practice in the tumbling technique, the general tendency is to lift the lens either directly forwards or forwards and slightly upwards. Both these movements are doomed to result in rupture of the capsule if the lens is held at 12 o'clock and the section passes through the limbus or sometimes even anterior to it, thus leaving a scleral ledge sufficiently long to overhang the equator of the lens and obstruct its delivery. It is only by first pushing the lens a little downwards that its upper edge can be eased out from under the scleral ledge. As soon as this happens, the lens is seen to spring forward a little as if released from pressure and to assume a globular shape when the cataract is soft. Complete iridectomy helps to visualize the upper edge of the lens as it comes out from under the ledge. Without relaxing his hold on the capsule, the surgeon then lifts the lens and delivers it with the support of a squint hook from below. When this procedure was followed there was a dramatic fall in the number of ruptured capsules. 


\section{Comment}

The literature on the use of alpha-chymotrypsin in cataract surgery (Thorpe, 1960; Barraquer, 1961) gives the impression that, in almost every case, the lens moves forwards and assumes a globular shape as soon as zonulolysis is complete. But this is not true; in my own small series I saw only two lenses do this, and in all other cases the upper edge had to be eased out from under the scleral ledge before the lens sprang forwards.

I feel that, for the lens to move forwards spontaneously, it has to be comparatively small, or else the corneo-scleral section has to pass through the sclera one or even two millimetres beyond the limbus. As these two conditions are not fulfilled in all cases, the lens remains stuck behind the scleral ledge and requires dextrous handling.

While making the section I aim to go through the limbus, but cases do occur in which the incision at certain places, especially at 12 o'clock, is either a little behind the limbus or a little in front of it. The scleral ledge is well marked if the incision lies in front of the limbus and it is not entirely absent even with a completely limbal incision.

\section{Summary}

The presence of scleral ledge after the cataract incision has been made is considered to be a frequent cause of rupture of the capsule even after the use of A.C.T. when extraction is attempted by holding the lens at 12 o'clock. A method is described of delivering the lens safely by avoiding the resistance of the scleral ledge.

\section{REFERENCES}

BARRAQUer, J. (1958). “Zonulolisis enzimatica”. Barcelona. (1961). A.M.A. Arch. Ophthal., 66, 6.

ThORPE, H. E. (1960). Amer. J. Ophthal., 49, 521. 